\title{
O LEAN THINKING EM UM PROCESSO PRODUTIVO: UM ESTUDO DE CASO EM UMA PRESTADORA DE SERVIÇOS DE LAVAGEM DE ROUPAS
}

\section{LEAN THINKING IN A PRODUCTIVE PROCESS: A CASE STUDY IN A LAUNDRY WASHING}

\section{A. D. CANAL ${ }^{1}$, L. BENINI $^{1 *}$, P. C. CAMARGOS ${ }^{1}$ e V. P. MARQUES ${ }^{1}$}

${ }^{1}$ Universidade Federal de Viçosa, Departamento de Engenharia de Produção e Mecânica, Viçosa, Minas Gerais, Brasil

${ }^{*}$ Autor correspondente. Universidade Federal de Viçosa, Departamento de Engenharia de Produção e Mecânica, Viçosa, Minas Gerais, Brasil, Phone: +55 31 36126500

Endereço de e-mail: lucasbenini@gmail

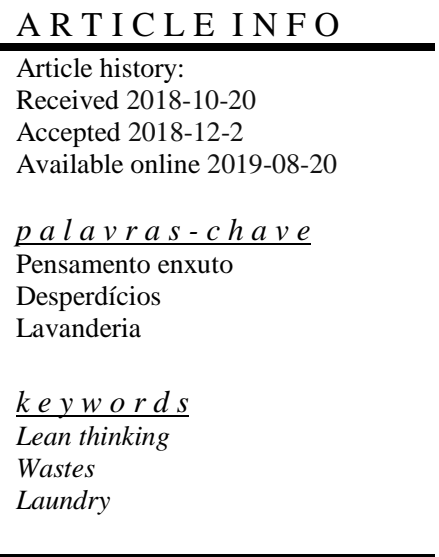

\begin{abstract}
RES U M O
A manufatura enxuta visa principalmente a eliminação de desperdícios por todo o processo e a exclusão do que não tem valor para o cliente. Neste sentido, o lean thinking pode ser aplicado aos mais diferentes tipos de processos produtivos. Este trabalho tem como objetivo principal a identificação dos desperdícios no processo de lavagem de roupa oferecido em uma lavanderia de médio porte. Foram aplicadas algumas ferramentas do lean thinking $e$ elaborados os mapas do estado atual e do estado futuro do processo de lavagem. Observouse que a etapa que é terceirizada pela empresa é a que mais exerce influência no lead time do processo.
\end{abstract}

\section{A B S T R A C T}

Lean manufacturing mainly aims to eliminate waste throughout the process and to exclude what is of no value to the customer. For this reason, lean thinking can be applied to the most different types of productive processes. This work has as main objective the waste identification in the laundry process offered in a medium-sized laundry. Some tools and techniques of lean thinking were applied in the washing process and the Value Stream Mapping of the current state and the future state were elaborated. It was observed that the stage that is outsourced by the company is the one that exerts most influence in the lead time of the process. 


\section{INTRODUÇÃO}

O modo de produção enxuta, também denominado lean manufacutring, é uma iniciativa que visa principalmente a eliminação de desperdícios por todo o processo, bem como excluir o que não tem valor para o cliente e imprimir velocidade à empresa. O lean thinking, ou pensamento enxuto, visa alinhar na melhor sequência as ações que criam valor e realizá-las de modo cada vez mais eficaz.

Quando se trata de manufatura enxuta, é muito comum exemplificar sua aplicação em um meio ambiente industrial complexo, com grandes volumes de estoque e alta produtividade. Porém os princípios e as ferramentas do lean thinking podem ser aplicáveis também em pequenas empresas ou processos do dia-a-dia. As origens do lean thinking datam do período Pós Segunda Guerra Mundial, quando o executivo da Toyota Taiichi Ohno iniciou, na década de 50, a criação e implantação de um sistema de produção cujo principal foco era a identificação e a posterior eliminação de desperdícios, com o objetivo de reduzir custos e aumentar a qualidade e a velocidade de entrega do produto aos clientes.

Ohno (1997) descreve que a filosofia do lean manufacturing visa produzir apenas o necessário, no momento necessário e na quantidade requerida. Taktica (2008), destaca ainda que "o lean é um sistema integrado de princípios, técnicas operacionais e ferramentas que levam à incessante busca pela perfeição na criação de valor para o cliente", gerando assim a redução de custos e aumento da qualidade e satisfação dos clientes.

O objetivo deste trabalho é identificar os desperdícios em um processo de lavagem de uma lavanderia e, através do emprego das ferramentas do lean thinking, propor possíveis melhorias para deixar o processo enxuto.

\section{OS SETE DESPERDÍCIOS}

No contexto do lean thinking visa-se reduzir ou eliminar os sete tipos de desperdício no processo produtivo: superprodução, tempo de espera, transporte, excesso de processamento, estoque, movimento e defeito. A seguir são abordados estes desperdícios (Ohno, 1997; Shing, 1996; Rocha, 2018):

- Superprodução: a superprodução é caracterizada pela produção além do volume programado, ou ainda, pela produção antecipada, ou seja, a perda por produzir antes do necessário, sendo gerado nos dois casos estoques desnecessários e que elevam os custos de operação. É totalmente desalinhado aos princípios do just in time;

- Tempo de espera: esta perda refere-se ao tempo ocioso em que nenhuma operação está sendo executada, podendo ocorrer por diversos motivos, como falta ou atraso de matéria-prima, desbalanceamento da produção, ineficácia do operador etc. Este tipo de perda é contraditório ao princípio do fluxo contínuo, conforme apresentado anteriormente;

- Transporte: a perda por transporte é caracterizada por deslocamentos desnecessários, sendo uma atividade que não gera valor e geralmente está atrelada ao desperdício de tempo. Uma das formas de reduzir este tipo de perda é a elaboração de um arranjo físico adequado;

- Excesso de processamento: é caracterizado pela realização de atividades desnecessárias durante o processamento para atribuir características de qualidade que não são exigidas pelo cliente;

- Estoque: é dado pela existência de níveis excessivos de materiais no almoxarifado, de produtos acabados e componentes entre processos. Tal perda contradiz o princípio da produção puxada;

- Movimento: é a realização de movimentos desnecessários por parte dos trabalhadores durante a execução de suas atividades. Este tipo de perda pode ocorrer devido à layouts ineficientes, duplicação de processos ou ainda devido à má comunicação ou armazenamento de produtos e materiais não identificados;

- Defeitos: é a perda por fabricação de produtos fora da especificação, não satisfazendo os requisitos do cliente. Isto significa desperdício de materiais, de disponibilidade de mão de obra e equipamentos.

Cabe destacar que o sistema de manufatura deve ser enxergado de maneira sistêmica, visando a otimização do sistema como um todo, através da eliminação de atividades e processos que não agregam valor para o cliente $\mathrm{e}$ da eliminação dos desperdícios citados acima (Rocha, 2018).

No lean thinking, desperdício é tudo o que não acrescenta valor ao produto na percepção do cliente. Nesse contexto, faz-se necessário medir e quantificar os resultados de eficiência e velocidade numa linha de produção. Para isso algumas métricas foram desenvolvidas. As principais métricas do lean são (Werkema, 2006):

- Lead Time: Também conhecido como tempo porta a porta, é o tempo necessário para um produto percorrer todas as etapas de um processo ou fluxo na visão do cliente. Pode-se citar como exemplo, em uma pizzaria delivery, o tempo desde o pedido até a entrega ao cliente. O importante, nessa métrica é descobrir o quão rápido o sistema entrega valor de forma repetitiva e confiável;

- Tempo de Ciclo: Tempo de produção propriamente dito. É a frequência com que uma peça ou produto é realmente completada em um processo, cronometrada por meio de observação. Inclui-se, também, o tempo que um operador leva para percorrer todos os seus elementos de trabalho antes de repeti-los (preparação, carregamento e descarregamento de materiais);

- Taxa de Saída (Throughput): Resultado de um processo ao longo de um período de tempo definido, expresso em unidade / tempo. Pode ser visualizada como um índice médio de conclusão, ou seja, representa quantos itens são concluídos a cada unidade de tempo (segundo, minuto, hora, etc.);

- Trabalho em Processo (Work in process - WIP): Conhecido como estoque em processo, é qualquer 
trabalho que esteja no processo e ainda não esteja concluído. Independentemente da quantidade de processos diferentes que possui a produção de determinado produto, se um item estiver dentro dos limites de um destes processos, ele estará em estoque de processo;

- Tempo de Setup ou Tempo de Troca (TR) (Changeover Time): É o tempo gasto para alterar a produção de um tipo de produto para outro. Um exemplo na usinagem, quando se modifica o material da peça de trabalho, deve-se modificar os parâmetros e a ferramenta utilizada, mesmo se a geometria inicial e final for a mesma. Este tempo que se leva acertando os parâmetros e modificando a ferramenta é o tempo de setup. É medido entre a fabricação da última peça do ciclo de produção que acabou de ser finalizado e a fabricação da primeira peça (que atenda aos requisitos de qualidade) do novo tipo de produto;

- Takt Time: Corresponde ao tempo disponível para a produção dividido pela demanda do cliente. Tem a função de sincronizar o ritmo de produção e vendas. Takt é uma palavra alemã, cujo significado é ritmo;

- Eficiência do Ciclo do Processo (PCE): Indicador que mede a relação entre o tempo de agregação de valor e o lead time.

\section{METODOLOGIA}

O processo definido para a identificação dos desperdícios foi a lavagem de roupas. Baseado na literatura especializada (Ohno, 1997; Liker 2005; Werkema 2006; Slack et al., 2009), foi executada a seguinte metodologia:

- Observação in loco de todos os processos (serviços) que são oferecidos pela lavanderia, registrando em imagens o leiaute e os elementos necessários ao estudo (máquinas, estoques, etc.);

- Seleção do processo para identificação dos desperdícios (considerando o processo com maior demanda na empresa);

- Elaboração e execução de questionário a ser respondido por funcionários e supervisores da empresa;

- Elaboração de um croqui (planta baixa) para representar os elementos do processo estudado;

- Identificação do fluxo de trabalho;

- Aplicação das métricas lean (lead time, work in process, cicle time, etc.) no processo estudado;

- Elaboração do mapa de estado atual e identificação dos desperdícios;

- Elaboração do mapa de estado futuro e proposição de possíveis melhorias.

Da visita à empresa foi observado um processo bastante simples e com fluxo de trabalho bem definido. Tomou-se a roupa suja como a matéria prima, e a roupa limpa, seca, passada, dobrada e embalada como o produto. Definiu-se o processo de lavagem conforme apresenta a Figura 1. A Figura 2 representa o croqui da lavanderia no estado atual.

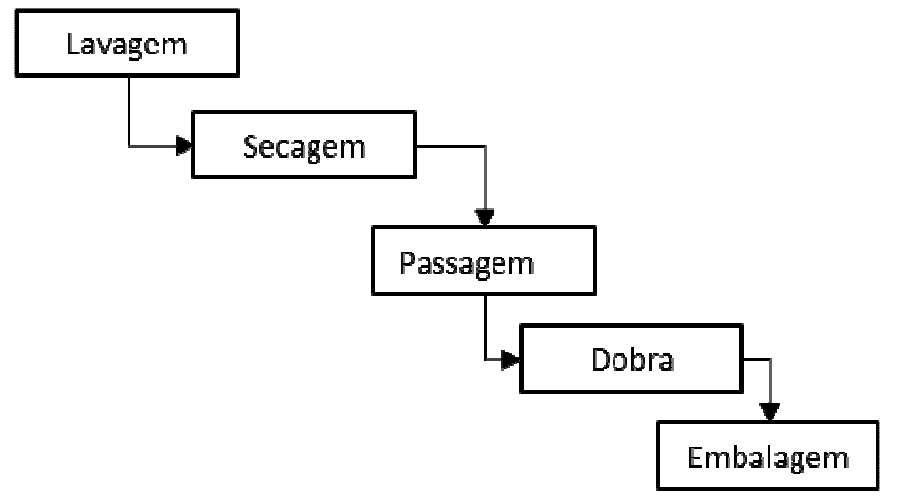

Figura - 1 Fluxo de trabalho identificado na lavanderia.

Foram identificadas 3 máquinas de lavar e 3 máquinas de secar. Para os dois tipos de máquinas havia duas de $10 \mathrm{~kg} \mathrm{e}$ uma de $17 \mathrm{~kg}$ de capacidade (Figura 3). Para o cálculo das métricas lean considerou-se a jornada diária de trabalho com 8 $\mathrm{h}$ de duração, sendo que são produzidos no máximo 10 cestos de roupa limpa (produto final); e a jornada de trabalho é dividida em dois turnos (manhã e tarde), cada um com $4 \mathrm{~h}$.

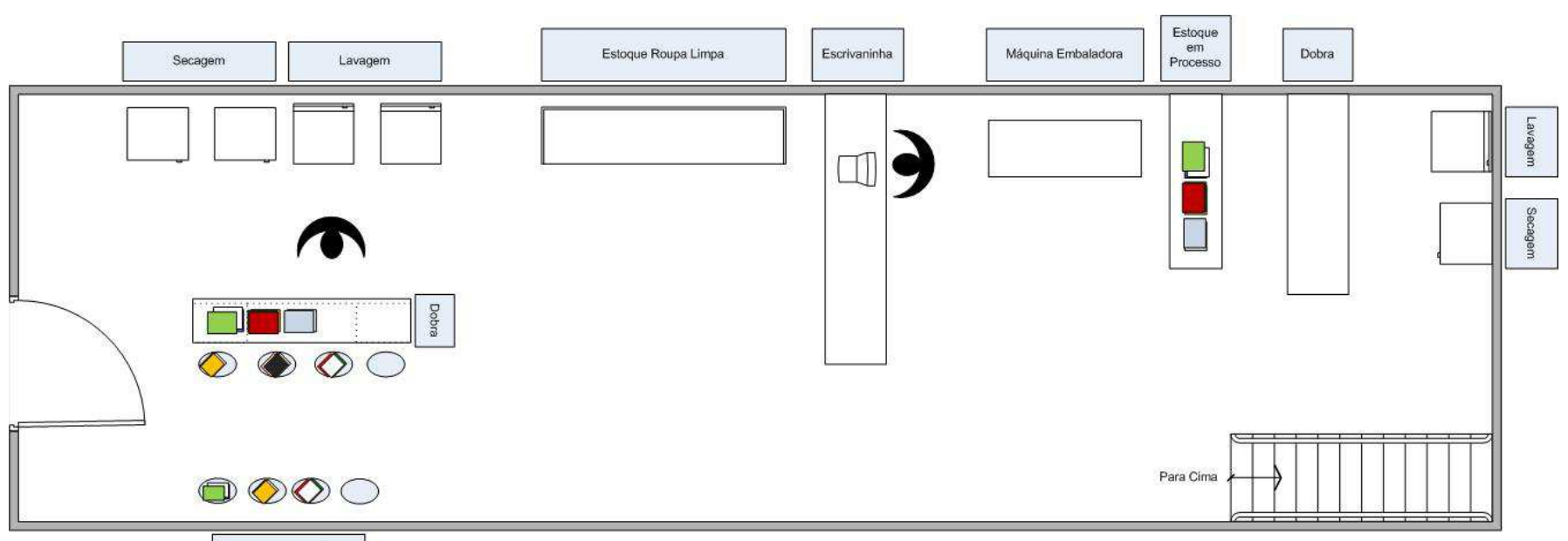

Estoque Roupa Suja

Figura 2 - Croqui da lavanderia. 

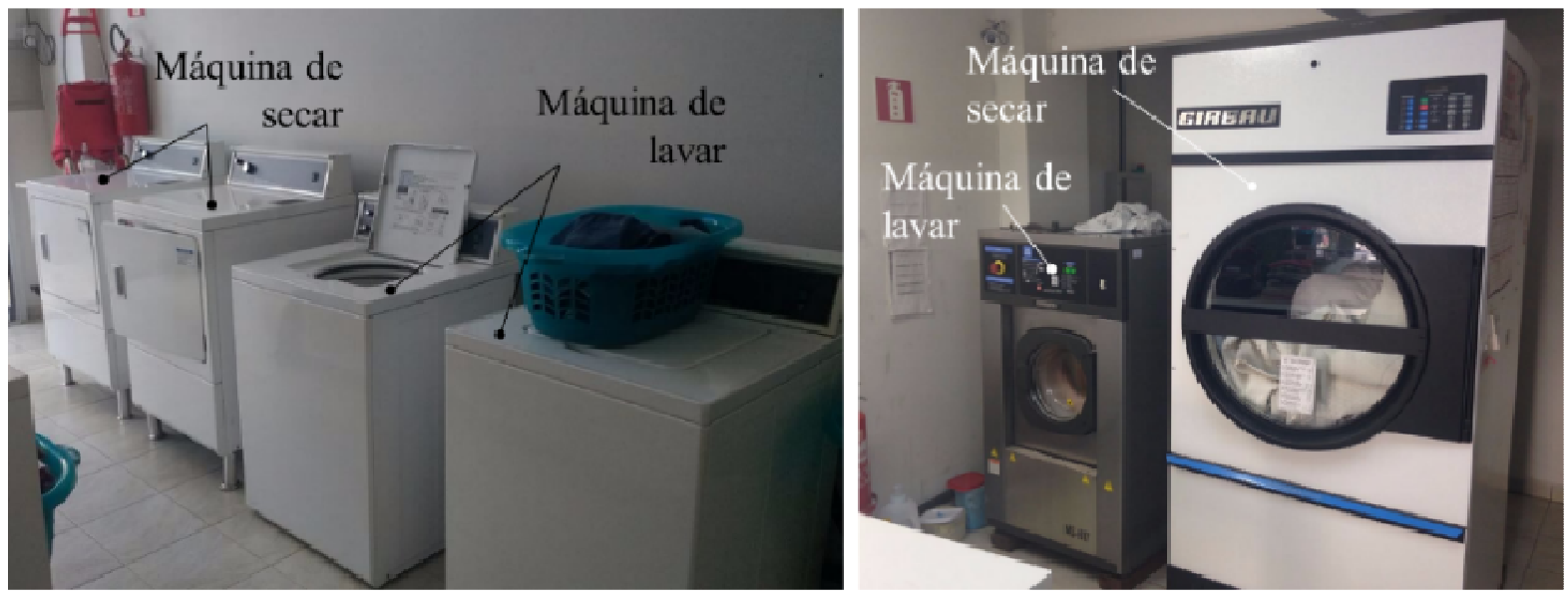

Figura 3 - Máquinas de lavar e de secar com capacidade de $10 \mathrm{~kg}$ e $17 \mathrm{~kg}$.

A lavanderia possui um quadro de agendamento (Figura 4) para o planejamento diário das suas operações. O cliente pode marcar através do telefone ou no local. Porém a adesão ao serviço de agendamento ainda é pouca por parte dos clientes, o que acaba gerando grande demanda em horários de pico.

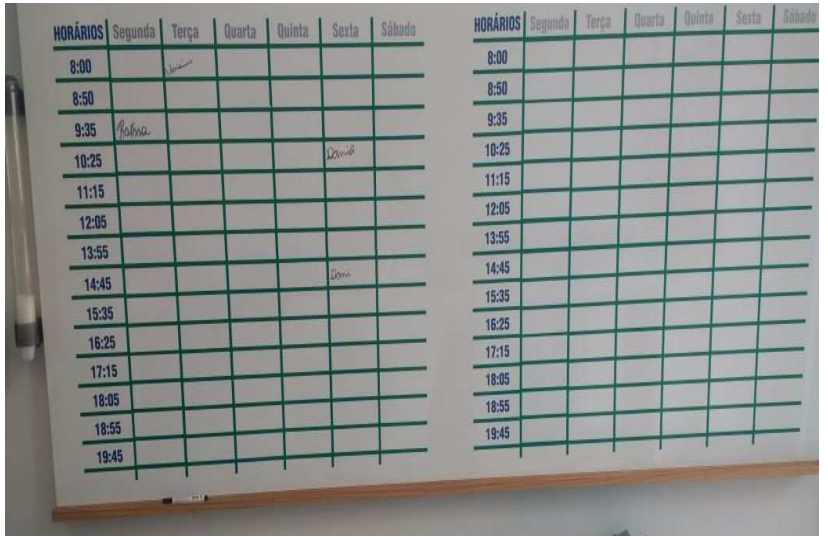

Figura 4 - Quadro de agendamento.

Cada etapa (Figura 1) processa no máximo 1 cesto de roupa (em média 25 camisetas), exceto no caso das máquinas de maior capacidade - as quais são utilizadas com 1 cesto e um edredom (colcha com grande volume). Porém como isso não altera o tempo de ciclo das máquinas considerou-se que elas trabalham sempre com a mesma quantidade de peças de roupa, de forma a simplificar o estudo. O cliente entrega a matéria prima (roupa suja) e por isso pode ser considerado também o fornecedor. A produção é de acordo com a demanda do cliente e por isso pode ser considerada como uma produção just in time. O dia de trabalho dura $8 \mathrm{~h}$ e nesse intervalo são produzidos no máximo 10 cestos de roupa limpa (produto final). E a produção é dividida em dois turnos, manhã e tarde, cada um com 4 horas.

Da visita à lavanderia, observou-se que há produção diária de 10 cestos de roupa limpa, sendo 5 cestos em cada turno. Destaca-se que a passagem de roupas é executada fora da empresa, ou seja, as peças de roupa presentes em estoque às 10:00 h na Lavanderia são transportadas até uma filial maior para que possam ser passadas manualmente, e retornam para a Lavanderia às 16:00 h, totalizando $6 \mathrm{~h}$ para a etapa de passagem. A Tabela 1 representa de forma resumida alguns fatores importantes para a aplicação das métricas lean.
Tabela 1 - Fatores do processo identificados na visita in loco.

\begin{tabular}{l|l}
\multicolumn{2}{c}{ Item } \\
\hline Quantidade de máq. de lavar & 3 \\
\hline Quantidade de máq. de secar & 3 \\
\hline Quantidade de operários & 2 \\
\hline Etapas do processo & 5 \\
\hline Quantidade de turnos por dia & 2 \\
\hline Matéria prima & $\begin{array}{l}\text { Roupa suja (mensurada em } \\
\text { cestos) }\end{array}$ \\
\hline Produto final & $\begin{array}{l}\text { Roupa limpa (mensurada } \\
\text { em cestos) }\end{array}$ \\
\hline $\begin{array}{l}\text { Quantidade de produtos } \\
\text { produzidos por dia }\end{array}$ & 10 cestos \\
\hline Tipo de produção & puxada \\
\hline
\end{tabular}

\section{RESULTADOS}

Foram identificados os tempos de ciclo (TC) para cada etapa, sendo para lavagem e secagem um tempo de $45 \mathrm{~min}$ cada um e para dobra e embalagem o TC foi de 5 min cada. O lead time (LT) foi calculado pelas Equações 5 e 6, somando-se os tempos de ciclo (Equações 1 e 2) e os tempos de não agregação de valor (Equações 3 e 4):

$T C_{\text {total }}=T C_{\text {lavagem }}+T C_{\text {secagem }}+T C_{\text {passagem }}+T C_{\text {dobra }}+T C_{\text {embalagem }}$

$T C_{\text {total }}=45+45+60+5+5=160 \mathrm{~min}$

onde $\mathrm{TC}_{\text {yotal }}$ é o Tempo de Ciclo Total [min], $\mathrm{TC}_{\text {lavagem é o }}$ Tempo de Ciclo da Lavagem [min], $\mathrm{TC}_{\text {secagem }}$ é o Tempo de

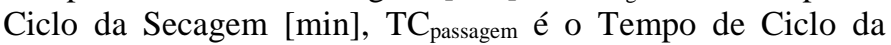
Passagem [min], $\mathrm{TC}_{\text {dobra }}$ é o Tempo de Ciclo da Dobra [min],

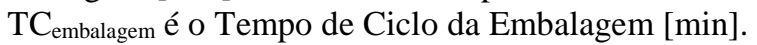

$$
\begin{aligned}
& N A T V_{\text {Total }}=N A T V_{\text {Lavagem }}+N A T V_{\text {Secagem }}+N A T V_{\text {Passagem }}+ \\
& N A T V_{\text {Dobra }}+N A T V_{\text {Embalagem }} \\
& N A T V_{\text {Total }}=5+5+300+5+5=320 \mathrm{~min}
\end{aligned}
$$

onde NATV $_{\text {Total }}$ é o Tempo de Não Agregação de Valor Total

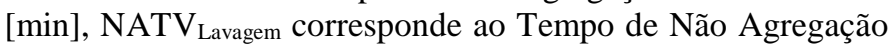

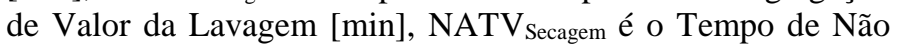
Agregação de Valor da Secagem [min], NATV corresponde ao Tempo de Não Agregação de Valor da

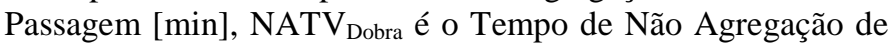


Valor da Dobra [min] e o NATV Embalagem corresponde ao Tempo de Não Agregação de Valor da Embalagem [min].

$L T=T C_{\text {Total }}+N A T V_{\text {Total }}$

$L T=160+320=480 \min$

onde LT corresponde ao lead time [min].

O trabalho em processo (WIP) também foi identificado como 5 cestos de roupa, já que a produção é dividida em dois turnos (manhã e tarde). O takt time foi calculado de acordo com a Equações 4 e 5 .

Takt time $=\frac{\text { Tempo Disponível da Produção }}{\text { Demanda do Cliente }}$

Takt time $=\frac{8 \text { horas }}{10 \text { cestos }}=0,8 \frac{h}{\text { cesto }}$

A eficiência do ciclo do processo (PCE) foi calculada de acordo com a Equações 6 e 7.

$P C E=\frac{T A V}{L T}=\frac{T A V_{\text {Lavagem }}+T A V_{\text {Secagem }}+T A V_{\text {Passagem }}}{L T}$

$P C E=\frac{45+45+60}{480}=0,3125$

onde TAV é o Tempo de Agregação de Valor [min] e LT corresponde ao lead time [min]

A aplicação das métricas lean identificou os tempos de processo (TP) que agregam valor para cada etapa do processo de lavagem, sendo para as etapas de lavagem e de secagem um tempo de $45 \mathrm{~min}$. Já para as etapas de dobra e de embalagem o TP foi de 5 min cada. Os demais resultados das métricas lean aplicadas no processo de lavagem são apresentados na Tabela 2. Em suma, o lead time é de $480 \mathrm{~min}$, sendo que 320 min são gastos em atividades que não agregam valor para o cliente.

Tabela 2 - Resultados das métricas lean aplicadas no processo de lavagem de roupas.

\section{Item}

Tempo de processo $\left(\mathrm{TP}_{\text {Total }}\right)$

Tempo de não agregação de valor total

(NATV Total $)$

Lead Time (LT)

Takt Time

Eficiência do ciclo do processo (EPC)

Taxa de saída (TP)

Os resultados apresentados na Tabela 2 foram inseridos no mapa do estado atual que é mostrado na Figura 5, sendo possível verificar visualmente as etapas de processo que mais geram desperdício para o processo.

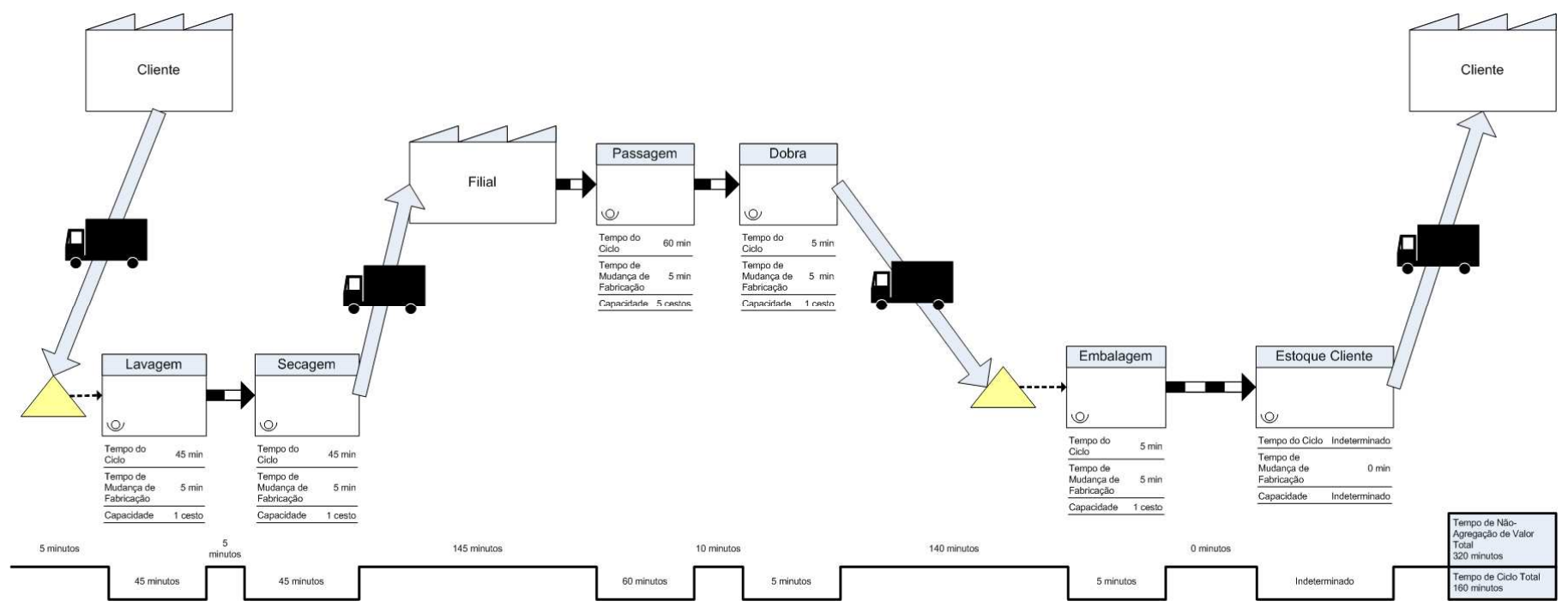

Figura 5 - Mapa do estado atual do processo de lavagem de roupa.

Ao longo do processo foram identificados os seguintes desperdícios:

- Espera: segundo a responsável o tempo médio de espera para um processo ser liberado (a secagem por exemplo) é $40 \mathrm{~min}$;

- Estoque: devido a não utilização do quadro de agendamento, pode-se perceber que o estoque de roupas limpas pode aumentar consideravelmente;

- Movimento: o leiaute do processo está organizado e não precisa necessariamente de reformulação para agilizálo;
- Transporte: esse desperdício é notado quando temos a etapa de passagem de roupa e temos o deslocamento para outra unidade para realizar essa tarefa. A roupa a ser passada é coletada as 10:00 h e entregue as 16:00 h do mesmo dia.

Para reduzir o tempo de não agregação de valor sugerem-se as seguintes ações:

- Espera: aquisição de novas máquinas para suprir a demanda;

- Estoque: promover uma maior adesão dos clientes para utilizar o quadro de agendamento; 
- Transporte: reposicionar a etapa de passagem de roupa na própria unidade.

Considerando estas ações de melhoria, o lead time do

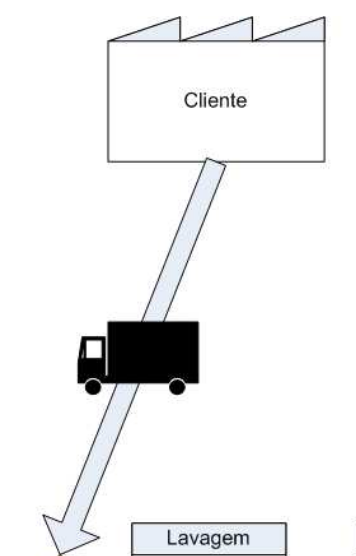
visualizada na Figura 6, que apresenta o mapa do estado futuro do processo de lavagem.

processo passaria para $175 \mathrm{~min}$ com apenas $25 \mathrm{~min}$ de tempos

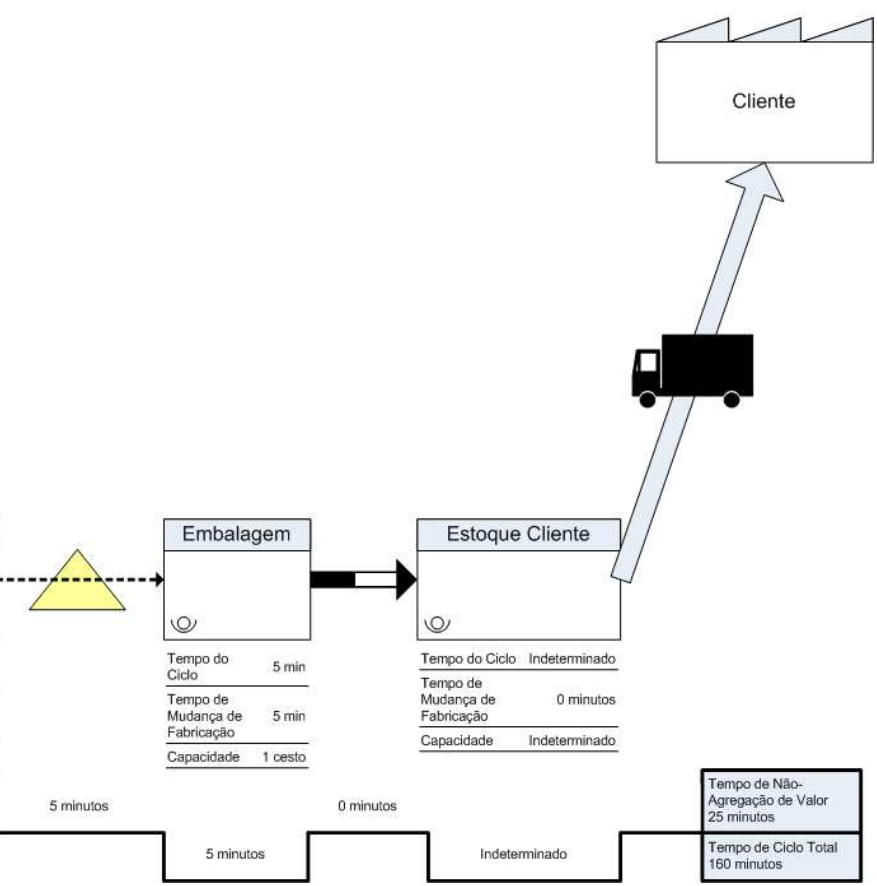

Figura 6 - Mapa do estado futuro do processo de lavagem de roupa.

\section{CONCLUSÕES}

Foram aplicadas algumas ferramentas e métricas do lean thinking em um processo de lavagem de roupa. Foram elaborados o mapa de estado atual e o mapa do estado futuro. Com estes resultados conclui-se que:

- Apesar do processo de lavagem de roupas ser relativamente simples quando comparado a outros processos industriais, foi possível identificar desperdícios que tem um grande impacto no lead time do processo;

- Efetuar o processo de passagem de roupas na própria empresa representa um impacto positivo do ponto de vista de lead time;

- Os tempos de processo, tanto os que agregam valor e os que não agregam valor, podem ser diminuídos, contudo é necessário investir em novos equipamentos;

- Não importa o tamanho ou a complexidade do processo, é necessário buscar a otimização do processo e evitar desperdícios visando sempre obter melhores resultados.
R E F E R E N C I A S

ANTUNES, J. Sistemas de Produção: Conceitos e práticas para o projeto e gestão da produção enxuta. Porto Alegre: Bookman, 2008.

LIKER, J. K. O modelo Toyota: 14 princípios de gestão do maior fabricante do mundo. Porto Alegre: Bookman, 2005.

OHNO, T. O sistema Toyota de producão: além da produção em larga escala. $1^{\text {a }}$. ed. Porto Alegre: Bookman, 1997.

ROCHA, F. Aplicação da filosofia Lean Service para a otimização do processo de serviço de uma Empresa Júnior de consultoria. Monografia (Graduação em Engenharia de Produção). Universidade Federal de Viçosa, MG, 2018.

SLACK, N.; CHAMBERS, S.; JOHNSTON, R. Administração da Produção. $3^{\text {a }}$. ed. São Paulo: Atlas, 2009.

TAKTICA. Consultoria. O que é Lean. Alphaville, Campinas: Ed. Business Center I, 2008. Disponível em: <www.taktica.com.br>. Acesso em 14 de agosto de 2018.

WERKEMA, C. Lean Seis Sigma: Introdução às ferramentas do Lean Manufacturing. $1^{\mathrm{a}}$. ed. Belo Horizonte: Werkema Editora, v. 4, 2006. 